\title{
Primary HIV Infection
}

Key words: acute infection, HIV, hepatitis

Primary human immunodeficiency virus (HIV) infection is a transient symptomatic illness associated with high-titer HIV1 replication and robust and expansive immunological responses to HIV. These acute symptomatic periods are likely critical determinants of the subsequent course of HIV disease. The initial infection of susceptible cells may vary somewhat with the route of infection. Viruses that enter via infected blood or blood products, maternal-to-fetal transmission, or sexual intercourse are likely cleared from the circulation to the spleen and other lymphoid organs, where they replicate to a critical level and then lead to a burst of viremia that disseminates virus throughout the body. Upon exposure of HIV-1, dendritic lineage cells may be the initial cells infected, which then pass virus onto CD4+ T cells or physically bring the virus into contact with CCR5+CD4+ T cells $(1,2)$. An "acute HIV syndrome," which occurs to varying degrees in approximately $50 \%$ of individuals with primary infection, have high levels of viremia that last for several weeks. The acute mononucleosis-like symptoms are well correlated with the presence of viremia and are indistinguishable from infectious mononucleosis (Table 1).

But some symptoms are particularly suggestive of acute HIV1 infection. A morbilliform rash, usually involving the trunk,

Table 1. Frequency of Symptoms and Findings Associated with Acute HIV-1 Infections

\begin{tabular}{lc}
\hline \multicolumn{1}{c}{ Symptom or Finding } & Occurrence \\
\hline Fever & $\mathrm{H}$ \\
Fatigue & $\mathrm{H}$ \\
Rash & $\mathrm{H}$ \\
Headache & $\mathrm{H}$ \\
Lymphadenopathy & $\mathrm{H}$ \\
Pharyngitis & $\mathrm{H}$ \\
Myalgia or arthralgia & $\mathrm{H}$ \\
"Nausea, vomiting, or diarrhea" & $\mathrm{M}$ \\
Night sweats & $\mathrm{H}$ \\
Aseptic meningitis & $\mathrm{M}$ \\
Oral ulcers & $\mathrm{L}$ \\
Genital ulcers & $\mathrm{L}$ \\
Thrombocytopenia & $\mathrm{M}$ \\
Leukopenia & $\mathrm{M}$ \\
Elevated hepatic-enzyme levels & $\mathrm{M}$ \\
\hline
\end{tabular}

$\mathrm{H}:>50 \%$, M: $20-50 \%, \mathrm{~L}:<20 \%$. occurs in 40 to 80 percent of persons. Acute meningoencephalitis syndrome has been reported as another presentation of acute HIV-1 infection (3). Other neurological manifestations such as Guillan-Barre syndrome and myelopathy have already been reported. Recently hepatic encephalopathy was also reported to be associated with primary HIV infection that was successufully treated with glucocorticoids (4).

See also p 1069.

In a group of 23 persons at risk of HIV infection who were followed every six months and who became infected, 87 percent had symptomatic acute infection, and 95 percent of these patients sought medical evaluation. But only one in four persons in the study received the appropriate diagnosis of acute HIV-1 infection at the first clinic visit, even though there should have been a high index of suspicion (5). Because the signs and symptoms are nonspecific, acute HIV-1 infection is frequently confused with a variety of other illnesses, including infectious mononucleosis, acute infection with hepatitis A or B, roseola or other viral infections. Acute HIV-1 infection should therefore be included in the differential diagnosis of any unexplained severe febrile illness.

The diagnosis of acute HIV-1 infection cannot be made with standard serologic tests. The recombinant enzyme-linked immunosorbent assays (ELISAs) commonly used to diagnose established HIV-1 infection are usually negative in persons who present with acute infection. Serologic tests first become positive approximately 22 to 27 days after acute infection. A blood sample should be obtained for both HIV-1 RNA testing (or p24 antigen testing, if HIV-1 RNA testing is not available) and HIV ELISA when a patient at risk presents with the signs and symptoms of the syndrome along with a compatible history of exposure. If these laboratory studies fail to detect HIV-1 infection, then other pathogens should be considered in the differential diagnosis. HIV ELISA and HIV-1 RNA tests should be repeated two to four weeks after the resolution of symptoms in high-risk persons.

Early therapy consisting of two nucleoside reverse-transcriptase inhibitors plus an HIV-1-protease inhibitor or three agents targeted to reverse transcriptase has also been investigated in several studies. To avoid continuous therapy throughout life, immune control of HIV-1 by interruptions in the treatment has been evaluated (6). Further studies await cofirmation. 
Toshio HATTORI, MD

Division of Allergy and Infectious Diseases, Graduate School of Medicine, Tohoku University,

1-1 Seiryo-machi, Aoba-ku, Sendai 980-8574

\section{References}

1) Kahn JO, Walker BD. Acute human immunodeficiency virus type 1 infection. New Engl J Med 339: 33-39, 1998.

2) Zaunders JJ, Kaufmann GR, Cunniggham PH, et al. Increase turnover of CCR5+ and redistribution of CCR5-T lymphocytes during primary human immunodeficiency virus type 1 infection. J Infect Dis 183: 736-743,
2001.

3) Narcison P, Galgani S, Grossan BD, et al. Acute disseminated encephalomyelitis as manifestation of primary HIV infection Neurology 57: 14931496, 2001.

4) Kobessho H, Matsushita A, Takahashi K, et al. Hepatic encephalopathy in primary human immunodeficiency virus type 1 (HIV-1) infection. Intern Med 41: 1069-1072, 2002.

5) Schacker T, Collier AC, Hughes J, Shea T, Corey L. Clinical and epidemiologic features of primary HIV infection. Ann Intern Med 125: 257264, 1996.

6) Rosenbrg ES, Altfeld M, Poon SH, et al. Immune control of HIV-1 after early treatment of acute infection. Nature 407: 523-526, 2000. 